Chapter 13

\title{
Metal Chalcogenides Tetrahedral Molecular Clusters: Crystal Engineering and Properties
}

\author{
Chun-Chang Ou and Chung-Sung Yang \\ Additional information is available at the end of the chapter \\ http://dx.doi.org/10. 5772/52660
}

\section{Introduction}

In recent years, the development of crystalline porous materials based on metal chalcogenides attracts scientific attention for their adjustable porous structures and potential applications in technology. In contrast to oxygen, for which only the di- and tri-nuclear homopolyatomic anions, i. e. $\mathrm{O}_{2}{ }^{2-}, \mathrm{O}_{2}{ }^{--}$and $\mathrm{O}_{3}{ }^{2-}$, are known in zeolite frameworks, the characteristic strong tendency of sulfur and the other elements of Group 16 is reflected in the wide range of polychalcogenide ions $X_{n}{ }^{2-}(X=S, S e, T e)$. The polychalcogenide $X_{n}{ }^{2-a r e}$ easily isolated as salts from polar solvents in the presence of suitable counter cations. [1]The choice of sulfides has many obvious advantages in the crystallization chemistry:[2] (a) In comparison with oxide and fluoride ions, the $\mathrm{S}^{2}$-ion has a much largerionic radius, which favors the tetrahedral coordination withcationsand allows the discovery of sulfide homologues of zeolites. (b) The higher polar ability of the $\mathrm{S}^{2}$-ion shows more flexibility for the structure of tetrahedra angles. For example, the tetrahedraT-S-T angle ranges from $109^{\circ}-161^{\circ}$. But the range of angle for tetrahedra $\mathrm{T}-\mathrm{O}-\mathrm{T}$ is $140^{\circ}-145^{\circ}$. ( $\mathrm{T}=$ tetrahedra metal atom, such as $\mathrm{In}$ ). $\mathrm{Ob}$ viously, the frameworks with higher flexibility will have better ability to accommodate various shapes of the templates, and the arrangement of tetrahedralunits in the dense matter can remain their original architectures.

Nowadays, chemists use inorganic clusters as molecular building blocks to create open framework with cavities and channels, including porous semiconductor, fast ion exchanger, shape- and size-selective catalysis, and optoelectronic applications. Among these clusters, only the metal chalcogenides tetrahedral molecular clusters can serve as artificial tetrahedral atoms, and assemble the tetrahedral clusters into porous open-framework through inorganic chalcogenides ligands. 
The study of metal chalcogenides tetrahedral molecular clusters provides a valuable opportunity to explore the synthetic and structural chemistry at the interface of chalcogenide molecular chemistry and solid-state chemistry. [3,4]A general introduction and overview of metal chalcogenides tetrahedral molecular clusters is intended in this chapter. In the following sections, a description of four basic types of metal chalcogenides tetrahedral molecular clusters will be provided. Design, synthesis strategy, and crystal engineering of building open-framework chalcogenides materials will be discussed. In addition, the interrelated properties of metal chalcogenides tetrahedral molecular clusters will be emphasized as the highlight of this paper.

\section{Classification of structure and mathematical extrapolation}

\subsection{Supertetrahedral clusters}

The simplest tetrahedral clusters of metal chalcogenides tetrahedral molecular clusters is supertetrahedral clusters, i. e. Tn clusters, with tetrahedral shaped fragments similar to the cubic ZnS-type lattice. [3-5] The supertetrahedral clusters were first denoted as $2^{|\mathrm{n}|}$ by Dance et al. [6] Recently, these compounds are denoted as Tn by Yaghi'sgroup. [4] In the formula, $\mathrm{n}$ is the number of metal layers. The mathematical of supertetrahedral clusters can be regarded as the analog of the ideal artificial tetrahedral atoms. The number of tetrahedra (T atoms) in a Tnsupertetrahedron is the nth tetrahedral number: $t_{n}=n(n+1)(n+2) / 6$. The number of distinct vertexes (X atoms) in one supertetrahedron is $t_{n+1}$. The formulas for discrete $\mathrm{T} n$ clusters are given as follows: T1 $\left(\mathrm{MX}_{4}\right), \mathrm{T} 2\left(\mathrm{M}_{4} \mathrm{X}_{10}\right), \mathrm{T} 3\left(\mathrm{M}_{10} \mathrm{X}_{20}\right), \mathrm{T} 4\left(\mathrm{M}_{20} \mathrm{X}_{35}\right)$ and $\mathrm{T} 5\left(\mathrm{M}_{35} \mathrm{X}_{56}\right)$, where $\mathrm{M}$ is a metal cation and $X$ is a chalcogen anion. [5] The illustration figures for Tn clusters are shown in Figure 1.

In an open-continuous framework, each of the four outermost vertexes of a supertetrahedron is shared with another supertetrahedron. Therefore, the overall composition is $\mathrm{T}_{\mathrm{x}} \mathrm{X}_{\mathrm{y}}$ with $x=t_{n}$ and $y=t_{n+1}-2$. In Tn clusters, all the $\mathrm{T}$ atoms are 4 -coordinated. Nevertheless, the $\mathrm{X}$ atoms possess 2-coordination sites (on the supertetrahedron edges and the outermost vertexes), 3-coordination sites (in the supertetrahedron faces), and 4-coordination sites (inside the cluster). In each corner linkedTn cluster $\left(\mathrm{T}_{\mathrm{x}} \mathrm{X}_{\mathrm{y}}\right)$, the number of 2-coordinated $\mathrm{X}$ atoms is $6 n-4$, and the number of 3-coordinated $X$ atoms is $2(n-1)(n-2)$. The 4 -coordinated sites will not appear, until the $n$ value reaches 4 or higher. When $n=4$ or higher, the number of 4-coordinated $\mathrm{X}$ atoms is $t_{n-3}$. For example, a T2 cluster consists of only 2-coordinated anions (e. g., $\mathrm{S}^{2-}$ ), and a T3 cluster has both 2- and 3-coordinated anions. Starting from the T4 cluster, tetrahedral coordination begins to adopt anions inside the cluster to create 4-coordinated anions, beside the existed 2- and 3-coordinated anions. [5]

In Table 1, the known T2 clusters, $\left[\mathrm{Ga}_{4} \mathrm{~S}_{10}\right]^{8-},[7]\left[\mathrm{In}_{4} \mathrm{Q}_{10}\right]^{8-},[8]\left[\mathrm{Ge}_{4} \mathrm{Q}_{10}\right]^{4-}(\mathrm{Q}=\mathrm{S}, \mathrm{Se}),[9]\left[\mathrm{Sn}_{4} \mathrm{Q}_{10}\right]^{4-}$ $(\mathrm{Q}=\mathrm{S}, \mathrm{Te}),[10]$ and examples of $\mathrm{T} 3$ clusters, $\left[\mathrm{In}_{10} \mathrm{~S}_{20}\right]^{10-},[11]\left[\mathrm{Ga}_{10} \mathrm{~S}_{16}\left(\mathrm{NC}_{7} \mathrm{H}_{9}\right)^{4}\right]^{2-},[12]$ and $\mathrm{In}_{10} \mathrm{~S}_{18}(\mathrm{HPP})_{6}\left(\mathrm{H}_{2} \mathrm{O}\right)_{15}$. [4](HPP=1,3,4,6,7,8-hexahydro-2H-pyrimido[1,2-a]pyrimidine) are provided. On the other hand, the reported T4 clusters, $\left[\mathrm{M}_{4} \mathrm{In}_{16} \mathrm{~S}_{33}\right]^{10-}\left(\mathrm{M}=\mathrm{Mn}^{2+}, \mathrm{Co}^{2+}, \mathrm{Zn}^{2+}, \mathrm{Cd}^{2+}\right)[13]$ and $\left[\mathrm{Cd}_{4} \mathrm{In}_{16} \mathrm{~S}_{35}\right]^{14-}[5]$ are provided in Table 1 , simultaneously. Up to date, the largest Tn clusters that has been prepared is $T 5$ cluster. The examples are $\mathrm{Cu}_{5} \operatorname{In}_{30} \mathrm{~S}_{54},[14]\left(\operatorname{In}_{34} \mathrm{~S}_{54}\right)^{6-}[15]$ and $\left(\operatorname{In}_{28} \mathrm{Cd}_{6} \mathrm{~S}_{56}\right)^{12-}$. [16] 
T2

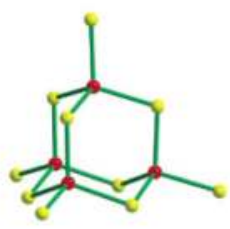

T4

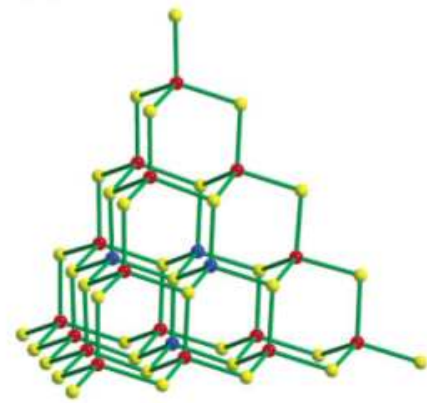

T3
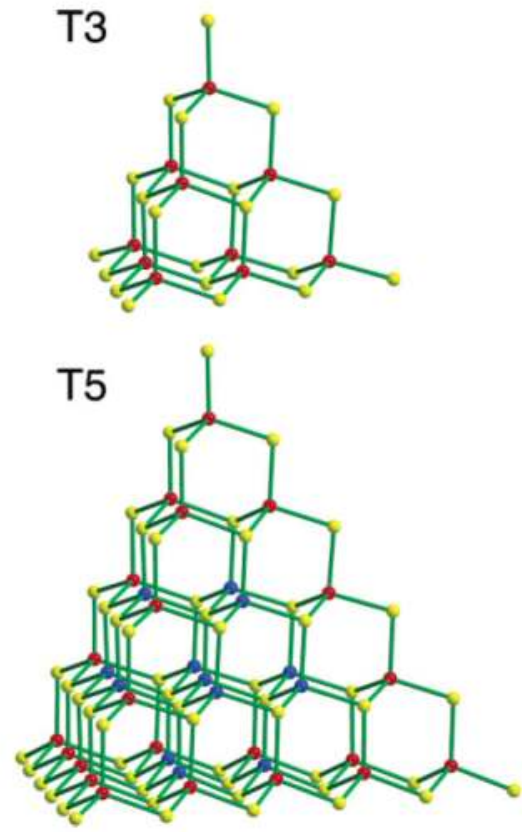

Figure 1. Illustration forTn series clusters, from T2 to T5. [3]

\begin{tabular}{|c|c|c|}
\hline Stoichiometry of Tn & examples & Ref. \\
\hline \multirow[t]{4}{*}{$\mathrm{T} 2\left(\mathrm{MX}_{4}\right)$} & {$\left[\mathrm{Ga}_{4} \mathrm{~S}_{10}\right]^{8-}$} & [7] \\
\hline & {$\left[\ln _{4} \mathrm{Q}_{10}\right]^{8-}(\mathrm{Q}=\mathrm{S}, \mathrm{Se})$} & [8] \\
\hline & {$\left[\mathrm{Ge}_{4} \mathrm{Q}_{10}\right]^{4-}(\mathrm{Q}=\mathrm{S}, \mathrm{Se})$} & 9 \\
\hline & {$\left[\mathrm{Sn}_{4} \mathrm{Q}_{10}\right]^{4-}(\mathrm{Q}=\mathrm{S}, \mathrm{Te})$} & [10] \\
\hline \multirow[t]{3}{*}{$\mathrm{T} 3\left(\mathrm{M}_{4} \mathrm{X}_{10}\right)$} & {$\left[\ln _{10} S_{20}\right]^{10-}$} & [11] \\
\hline & {$\left[\mathrm{Ga}_{10} \mathrm{~S}_{16}\left(\mathrm{NC}_{7} \mathrm{H}_{9}\right)^{4}\right]^{2-}$} & {$[12]$} \\
\hline & $\mathrm{In}_{10} \mathrm{~S}_{18}(\mathrm{HPP})_{6}\left(\mathrm{H}_{2} \mathrm{O}\right)_{15}$ & {$[4]$} \\
\hline \multirow[t]{2}{*}{$\mathrm{T} 4\left(\mathrm{M}_{10} \mathrm{X}_{20}\right)$} & {$\left[\mathrm{M}_{4} \mathrm{In}_{16} \mathrm{~S}_{33}\right]^{10-}\left(\mathrm{M}=\mathrm{Mn}^{2+}, \mathrm{CO}^{2+}, \mathrm{Zn}^{2+}, \mathrm{Cd}^{2+}\right)$} & [13] \\
\hline & {$\left[\mathrm{Cd}_{4} \ln _{16} \mathrm{~S}_{35}\right]^{14-}$} & {$[5]$} \\
\hline \multirow[t]{3}{*}{$\mathrm{T} 5\left(\mathrm{M}_{35} \mathrm{X}_{56}\right)$} & $\mathrm{Cu}_{5} \ln _{30} \mathrm{~S}_{54}$ & {$[14]$} \\
\hline & $\left(\ln _{34} S_{54}\right)^{6-}$ & {$[15]$} \\
\hline & $\left(\ln _{28} \mathrm{Cd}_{6} \mathrm{~S}_{56}\right)^{12-}$ & {$[16]$} \\
\hline
\end{tabular}

Table 1. Supertetrahedral clusters base on metal chalcogenides tetrahedral molecular clusters 


\subsection{Pentasupertetrahedral clusters (Pn)}

The second series of tetrahedral clusters is known as pentasupertetrahedral clusters, shown in Figure 2. This series cluster was denoted as $5^{\text {[n\} }}$ by Dance et al. [6] and was named as $\mathrm{P} n$ by Feng'sgroup. [17] The Pn cluster is composed of four same order Tn clusters at the corner and one anti-Tn cluster at the core. In comparison, a pentasupertetrahedral cluster is considerably larger than a supertetrahedral cluster of the same order. For example: the P1 cluster consists four T1 clusters $\left(\mathrm{MX}_{4}\right)$ and one anti-T1 $\left(\mathrm{XM}_{4}\right)$ cluster at the center, resulting in the composition $\left(\left(\mathrm{MX}_{4}\right)_{4}\left(\mathrm{XM}_{4}\right)\right.$ (i. e., $\left.\mathrm{M}_{8} \mathrm{X}_{17}\right)$. The supertetrahedral clusters as large as $\mathrm{T} 5$ are known, but the largest known cluster of the Pn series is the P2 cluster. [17]
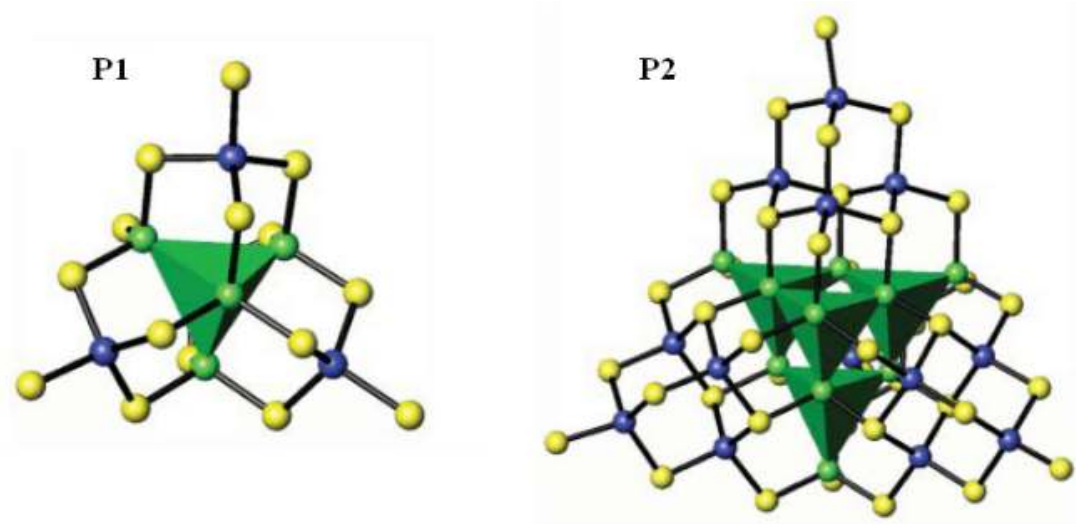

Figure 2. Illustration for Pn series clusters, from P1 to P2. A polyhedral representation is used for the central antisupertetrahedral cluster. [30]

Some examples of P1 clusters, $\left[\mathrm{SCd}_{8}(\mathrm{SBu})_{12}\right](\mathrm{CN})_{4 / 2,}[18]\left(\mathrm{SBu}=\mathrm{n}\right.$-butanethiolate ) $\left[\mathrm{M}_{4} \mathrm{Sn}_{4} \mathrm{~S}_{17}\right]^{10-}$ $\left(\mathrm{M}=\mathrm{Mn}^{2+}, \mathrm{Fe}^{2+}, \mathrm{Co}^{2+}, \mathrm{Zn}^{2+}\right),[19]$ and $\left[\mathrm{M}_{4} \mathrm{Sn}_{4} \mathrm{Se}_{17}\right]^{10-}\left(\mathrm{M}=\mathrm{Mn}^{2+}, \mathrm{Co}^{2+}, \mathrm{Zn}^{2+}\right),[20,21]$ and $\mathrm{P} 2$ clusters, $\left[\mathrm{Li}_{4} \mathrm{In}_{22} \mathrm{~S}_{44}\right]^{18-}$ in ICF-26[22](ICF= Inorganic ChalcogenideFramework) and $\left[\mathrm{Cu}_{11} \mathrm{In}_{15} \mathrm{Se}_{16}(\mathrm{SePh})_{24}\left(\mathrm{PPh}_{3}\right)_{4}\right]$. [23] (Ph= phenyl group, PPh3=triphenylphosphine group) are given in Table 2.

\begin{tabular}{clc}
\hline Stoichiometry of Pn & \multicolumn{1}{c}{ examples } & Ref. \\
\hline $\mathrm{P} 1\left(\mathrm{M}_{8} \mathrm{X}_{17}\right)$ & {$\left[\mathrm{SCd}_{8}(\mathrm{SBu})_{12}\right](\mathrm{CN})_{4 / 2}$} & {$[18]$} \\
\hline & {$\left[\mathrm{M}_{4} \mathrm{Sn}_{4} \mathrm{~S}_{17}\right]^{10-}\left(\mathrm{M}=\mathrm{Mn}^{2+}, \mathrm{Fe}^{2+}, \mathrm{CO}^{2+}, \mathrm{Zn}^{2+}\right)$} & {$[19]$} \\
\hline & {$\left[\mathrm{M}_{4} \mathrm{Sn}_{4} \mathrm{Se}_{17}\right]^{10-}\left(\mathrm{M}=\mathrm{Mn}^{2+}, \mathrm{CO}^{2+}, \mathrm{Zn}^{2+}\right)$} & {$[20,21]$} \\
\hline $\mathrm{P} 2\left(\mathrm{M}_{26} \mathrm{X}_{44}\right)$ & {$\left[\mathrm{Li}_{4} / \mathrm{n}_{22} \mathrm{~S}_{44}\right]^{18-}$} & {$[22]$} \\
\hline & {$\left[\mathrm{Cu}_{11} \mathrm{In}_{15} \mathrm{Se}_{16}\left(\mathrm{SePh}_{24}\left(\mathrm{PPh}_{3}\right)_{4}\right]\right.$.} & {$[23]$} \\
\hline
\end{tabular}

Table 2. Pentasupertetrahedral clusters base on metal chalcogenides tetrahedral molecular clusters 


\subsection{Capped supertetrahedral clusters (Cn)}

The third series of tetrahedral clusters is capped-supertetrahedral clusters, as shown in Figure 3. This series clusterwas denoted as $7^{(n)}$ by Dance et al. [6] Recently, the series clusterwas named as C $n$ by Feng's group. [3] The capped supertetrahedral clusters are defined as a regular supertetrahedral cluster $(\mathrm{T} n)$ at the core covered with a shell of atoms, which is also related to the Tn cluster. Accurately, each face of the Tn core unit is covered with a single sheet of atoms called the $\mathrm{T}(n+1)$ sheet and each corner of this cluster is covered with a MX group. The $\mathrm{T}(n+1)$ sheet is defined as the bottom atomic sheet of a $\mathrm{T}(n+1)$ cluster. [3]
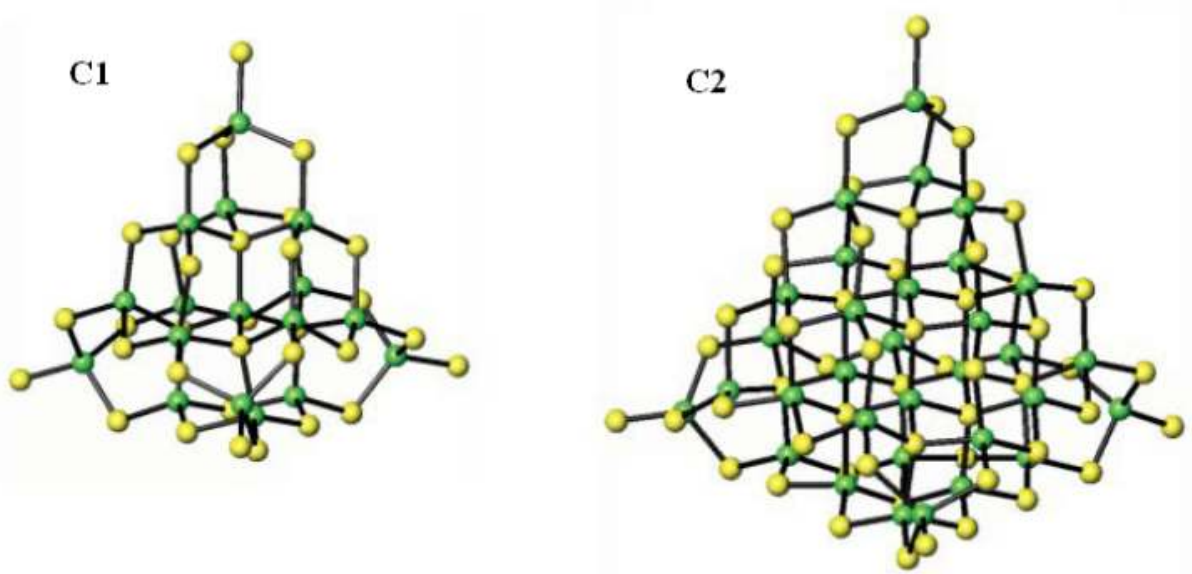

Figure 3. Illustration for Cn series clusters, from C1 to C2. (adopted from Ref 30)[30]

As shown in Table 3, the first metal chalcogenides tetrahedral molecular clusters of $\mathrm{C} 1$ clusters is $\left[\mathrm{S}_{4} \mathrm{Cd}_{17}(\mathrm{SPh})_{28}\right]^{2-}$ [18], ( $\mathrm{SPh}=$ benzenethiol ligand), by Dance group in 1988. In later days, two new $\mathrm{Cl}$ clusters were reported. They are $\mathrm{Cd}_{17} \mathrm{~S}_{4}\left(\mathrm{SCH}_{2} \mathrm{CH}_{2} \mathrm{OH}\right)_{26}$ [24] and $\left[\mathrm{S}_{4} \mathrm{Cd}_{17}(\mathrm{SPh})_{24}\left(\mathrm{CH}_{3} \mathrm{OCS}_{2}\right)_{4 / 2}\right]_{\mathrm{n}} \mathrm{nCH}_{3} \mathrm{OH}$. [25]As for the $\mathrm{C} 2$ clusters, three clusters, $\mathrm{Cd}_{32} \mathrm{~S}_{14}\left(\mathrm{SCH}_{2} \mathrm{CH}(\mathrm{OH}) \mathrm{CH}_{3}\right)_{36}$. $4 \mathrm{H}_{2} \mathrm{O},[26] \quad \mathrm{Cd}_{32} \mathrm{~S}_{14}\left(\mathrm{SC}_{6} \mathrm{H}_{5}\right)_{36} . \quad(\mathrm{DMF})_{4},[27] \quad$ and $\mathrm{Cd}_{32} \mathrm{Se}_{14}(\mathrm{SePh})_{36}\left(\mathrm{PPh}_{3}\right)_{4}[28]$ have been successfully synthesized, so far.

\begin{tabular}{clr}
\hline Stoichiometry of $\mathbf{n}$ & examples & Ref. \\
\hline $\mathrm{C} 1\left(\mathrm{M}_{17} \mathrm{X}_{32}\right)$ & {$\left[\mathrm{S}_{4} \mathrm{Cd}_{17}\left(\mathrm{SPh}_{28}\right]^{2-}\right.$} & {$[18]$} \\
\hline & $\mathrm{Cd}_{17} \mathrm{~S}_{4}\left(\mathrm{SCH}_{2} \mathrm{CH}_{2} \mathrm{OH}\right)_{26}$ & {$[24]$} \\
\hline & {$\left[\mathrm{S}_{4} \mathrm{Cd}_{17}\left(\mathrm{SPh}_{24}\left(\mathrm{CH}_{3} \mathrm{OCS}\right)_{4 / 2}\right]_{n} \mathrm{nCH}_{3} \mathrm{OH}\right.$} & {$[25]$} \\
\hline $\mathrm{C} 2\left(\mathrm{M}_{32} \mathrm{X}_{54)}\right.$ & $\mathrm{Cd}_{32} \mathrm{~S}_{14}\left(\mathrm{SCH}_{2} \mathrm{CH}(\mathrm{OH}) \mathrm{CH}_{3}\right)_{36} \cdot 4 \mathrm{H}_{2} \mathrm{O}$ & {$[26]$} \\
\hline & $\mathrm{Cd}_{32} \mathrm{Se}_{14}\left(\mathrm{SePh}_{36}\left(\mathrm{PPh}_{3}\right)_{4}\right.$ & {$[27]$} \\
\hline & $\mathrm{Cd}_{32} \mathrm{~S}_{14}\left(\mathrm{SC}_{6} \mathrm{H}_{5}\right)_{36} .(\mathrm{DMF})_{4}$ & {$[28]$} \\
\hline
\end{tabular}

Table 3. Capped-supertetrahedral clusters base on metal chalcogenides tetrahedral molecular clusters 


\subsection{Super-supertetrahedral clusters $(T p, q)$}

Besides theseries of tetrahedral molecular clusters, a special multi-series metal chalcogenides hollow cluster has been reported, simultaneously. These metal chalcogenides hollow clusters are known as super-supertetrahedral clusters, denoted as Tp,q. [29]This series of cluster is built in a $\mathrm{T} q$ supertetrahedron of $\mathrm{T} p$ supertetrahedra. The number of tetrahedra (T atoms) in a T $p$ supertetrahedron is the $p$ th tetrahedral number, $t_{p}=p(p+1)(p+2) / 6$, and the number of $X$ atoms is $t_{p}+1$. In a T $p, q$ super-supertetrahedron the number of $T$ atoms is tqtp, and the number of $X$ atoms is $t q\left(t_{p+1}-2\right)+2$. The first metal chalcogenides tetrahedral molecular clusters of T $p, q$ clusters is CdInS-420, i. e. T4,2 ( given in Figure 4), prepared by Yaghi group. [29]
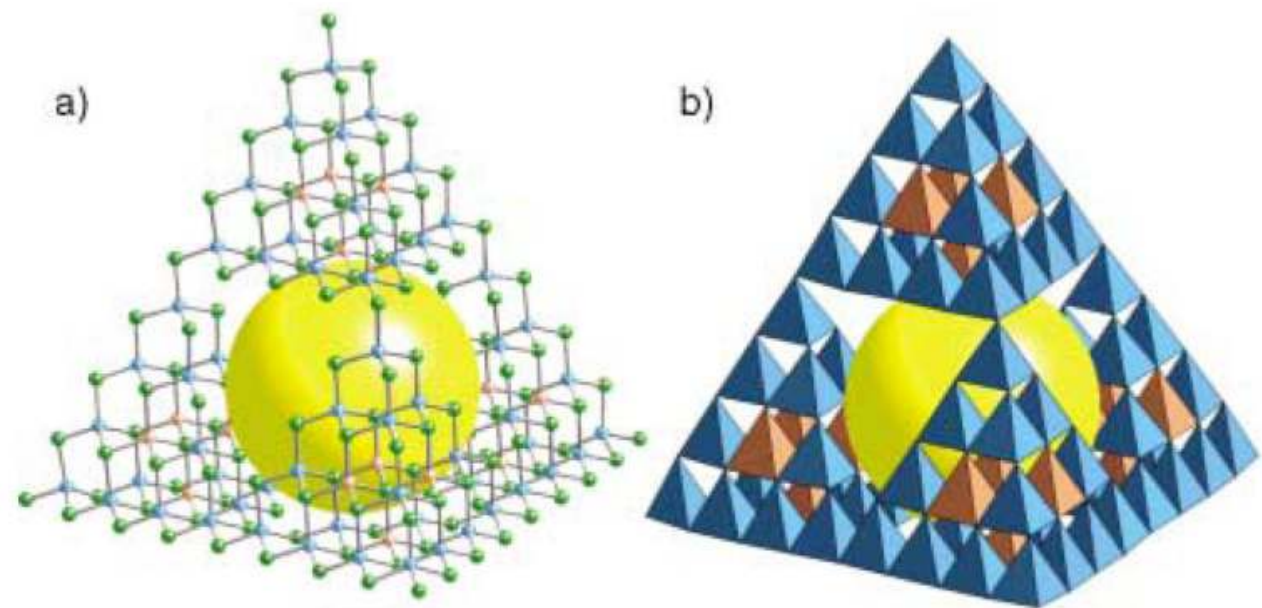

Figure 4. a) The CdInS-420 cluster as a ball and stick model. In (blue); Cd (orange); $\mathrm{S}$ (green). The large yellow sphere indicates the central cavity. (b) The same view as (a) shown as metal-centered tetrahedra. [29]

\section{Design and synthesis: Crystal engineering}

The explosive growth in the number of microporous and open framework materials is mainly contributed by the numerous variable synthetic and structural parameters. It is known that each Tn cluster behaves as an artificial tetrahedral atom ( $\mathrm{T}$ atom). These $\mathrm{T}$ atoms link with others by four vertex chalcogenides (ex: sulfur) atoms into the nanoclusters to produce extended open frameworks. Among these clusters, the use of structure-directing agents with different charge, size, and shape is particularly effective to assist the formation of oxide frameworks. [3-5]Furthermore, the conventional synthetic methods to prepare the metal 
chalcogenides tetrahedral molecular clusters include the crystallization from solution[6, $30-31]$ and the hydrothermal synthetic route. [2-5, 13]

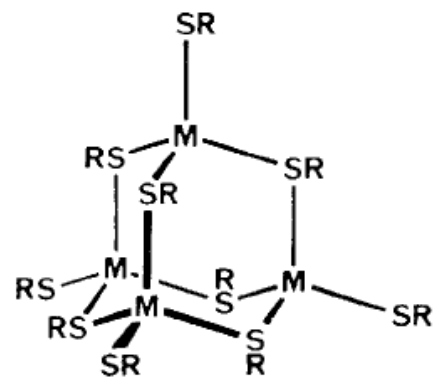

(1) $\left[\mathrm{M}_{4}(\mathrm{SR})_{10}\right]^{2-}$
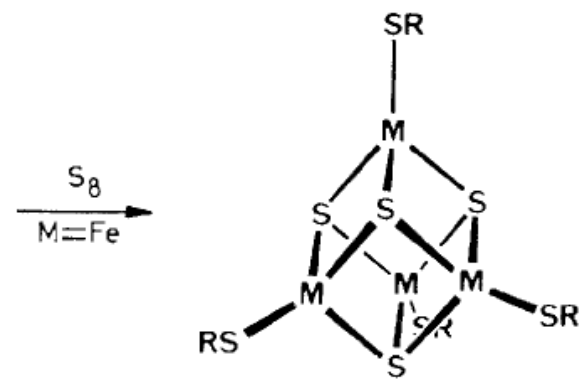

(2) $\left[\mathrm{S}_{4} \mathrm{Fe}_{4}(\mathrm{SR})_{4}\right]^{2-}$

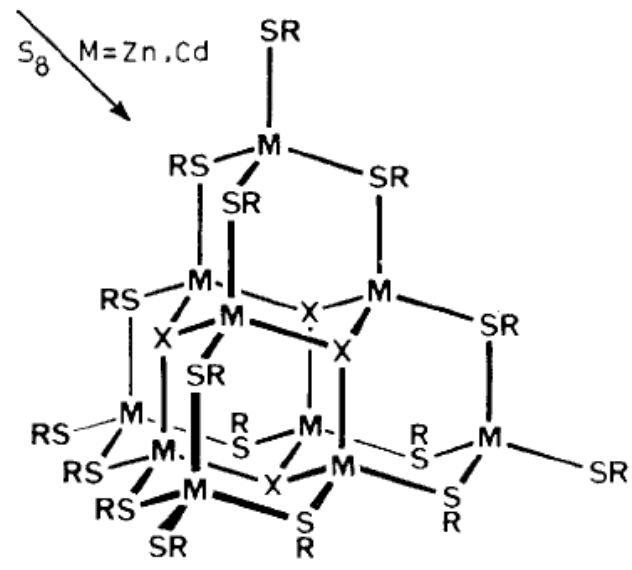

$$
\text { (3) } \mathrm{x}=\mathrm{S} \quad\left[\mathrm{S}_{4} \mathrm{M}_{10}(\mathrm{SR})_{16}\right]^{4-}
$$

Figure 5. $\left[\mathrm{M}_{4}(\mathrm{SPh})_{10}\right]^{2-}, \mathrm{M}=\mathrm{Fe}, \mathrm{Co}, \mathrm{Zn}(\mathbf{1})$ and probably $\mathrm{Cd}$ react with sulphur and different metal cation (i. e., $\left.\mathrm{Fe}, \mathrm{Zn}, \mathrm{Cd}\right)$ in acetonitrile to yield the $\left[\mathrm{Fe}_{4} \mathrm{~S}_{4}(\mathrm{SPh})_{4}\right]^{2-}(2)$ and $\left[\mathrm{S}_{4} \mathrm{M}_{10}(\mathrm{SPh})_{16}\right]^{4-}, \mathrm{M}=\mathrm{Zn}, \mathrm{Cd}$ (3). [31]

Prior to the development of open framework chalcogenides, tetrahedral clusters were not commonly encountered among open framework solids. In 1982, Dance group reported the extension reaction of $\mathrm{T} 2$ cluster, $\left[\mathrm{M}_{4}(\mathrm{SPh})_{10}\right]^{2-}\left(\mathrm{M}=\mathrm{Zn}^{2+}, \mathrm{Cd}^{2+}\right)$ with sulphur, including the metals zinc and cadmium in acetonitrile, to yield a different and unprecedented product $\left(\mathrm{Me}_{4} \mathrm{~N}\right)_{4}\left[\mathrm{~S}_{4} \mathrm{M}_{10}(\mathrm{SPh})_{16}\right]\left(\mathrm{M}=\mathrm{Zn}^{2+}, \mathrm{Cd}^{2+}\right)$, shown in Figure 5. [31]A similar crystallization from 
solution reactions with elemental selenium yields analogous complexes $\left(\mathrm{Me}_{4} \mathrm{~N}_{4}\right)$ $\left[\mathrm{Se}_{4} \mathrm{M}_{10}(\mathrm{SPh})_{16}\right]\left(\mathrm{M}=\mathrm{Zn}^{2+}, \mathrm{Cd}^{2+}\right)$. Therefore, a set of four homologous complexes, $\left(\mathrm{Me}_{4} \mathrm{~N}_{4}\right)$ $\left[\mathrm{X}_{4} \mathrm{M}_{10}(\mathrm{SPh})_{16}\right]\left(\mathrm{M}=\mathrm{Zn}^{2+}, \mathrm{Cd}^{2+} ; \mathrm{X}=\mathrm{S}^{2-}, \mathrm{Se}^{2-}\right)$ have been prepared by this method. The four anions have the same molecular aggregation structure, i. e. a supertetrahedral 10-metal section of the cubic (sphalerite) metal chalcogenide structure. Nowadays, the unprecedented product $\left(\mathrm{Me}_{4} \mathrm{~N}\right)_{4}\left[\mathrm{~S}_{4} \mathrm{M}_{10}(\mathrm{SPh})_{16}\right]\left(\mathrm{M}=\mathrm{Zn}^{2+}, \mathrm{Cd}^{2+}\right)$ is known as the T3 series clusters. The hydrothermal synthesis of open framework chalcogenidesis started with simple elemental forms (e. g., sulfur) and inorganic salts. The initial process usually involves redox chemistry in the formation of clusters. Clusters of various types and sizes could coexist in a solution. Equilibria between various clusters in solution would shift to the direction that favors the creation of one or more clusters, when crystallization involving these clusters occurs. [3]

\subsection{Chalcogenides with different valence state of metal cations}

Metal chalcogenides tetrahedral molecular clusters in the self-assembly process is critical for the synthesis of microporous and mesoporous oxides. [32] The known example is aluminophosphates open-frameworks with divalent metal cations $\left(\mathrm{M}^{2+}\right)$. The existence of $\mathrm{M}^{2+}$ can provide a rather flexible adjustment of the framework charge density and therefore makes it easier to achieve the charge matching of whole compound. In metal chalcogenides tetrahedral molecular clusters, the ratio between metal cations of different valences subjects to the limitation of the local charge balance within each cluster and may not be as flexible as that in the oxides analogue. $[3,29]$

The classes of open framework materials are dominated by typical zeolites, such as ZSM-5, (named after Zeolite Socony Mobil by mobiloil company). The sodalite structure can be made in the neutral $\mathrm{SiO}_{2}$ form. Neutral porous frameworks are also found in $\mathrm{AlPO}_{4}$ and $\mathrm{GeO}_{2}$ forms. Therefore, it is reasonable to expect the existence of open framework sulfides with framework composition of $\mathrm{GeS}_{2}$ or $\mathrm{SnS}_{2}$. The early development of metal chalcogenides tetrahedral molecular clusters is the preparation of open framework sulfides by using the mono- or divalent cations (e. g., $\mathrm{Cu}^{+}, \mathrm{Mn}^{2+}$ ) to join the metal chalcogenides tetrahedral molecular clusters together (i. e. $\mathrm{Ge}_{4} \mathrm{~S}_{10}{ }^{4-}$ ). [17] These low-valentcations can generate negative charges on the framework. Subsequently, the charge is balanced by structure-directing amine molecules. For example, the compounds prepared with the formula of $\left[\left(\mathrm{CH}_{3}\right)_{4} \mathrm{~N}_{2}\left[\mathrm{MGe}_{4} \mathrm{~S}_{10}\right]\left(\mathrm{M}=\mathrm{Mn}^{2+}, \mathrm{Fe}^{2+}, \mathrm{Cd}^{2+}\right)\right.$, by Yaghigroup. [7]In this case, the $\mathrm{MnGe}_{4} \mathrm{~S}_{10}$. $2\left(\mathrm{CH}_{3}\right)_{4} \mathrm{~N}$, has a non-interpenetrating diamond type lattice (the single diamond type) with alternating T2 and T1 clusters to occupy the tetrahedral nodes. In the Ge-S or Ge-Se system of metal chalcogenides tetrahedral molecular clusters, the largest metal chalcogenidessupertetrahedral molecular cluster is T2. As a result, a perspective charge-balance problem of metal chalcogenides tetrahedral molecular clusters system is proposed. [17]In the Ge-S or Ge-Se system of metal chalcogenides tetrahedral molecular clusters, Feng's group found that clusters larger than T2 cannot be prepared in this system. The reason is that the charge at cation sites is too high to satisfy the coordination environment of 3-coordinated anion sites in clusters larger than T2. For the same reason, it is not surprise to find that no regular T3 cluster can besuccessfully prepared in the pure Sn-S (or Sn-Se) system. 
In In-S system of metal chalcogenides tetrahedral molecular clusters, Yaghi'sgroup used the In-S composition to build a unique porous sulfide-based frame work materials. [4-5] Its uniqueness comes from $50 \%$ or more framework cation sites in zeolite-like oxides with a valence $\geqq 4$. The linkage in In-O-In or Al-O-Al is not similar to that in zeolite-like oxides because of the Loewenstein rule. The Loewenstein rule states that the ratio of $\mathrm{M}^{4+} / \mathrm{M}^{3+}$ should be larger or equal to one. [17] The most common in the In-S system is the occurrence of the T3 cluster, $\left[\mathrm{In}_{10} \mathrm{~S}_{20}\right]^{10-}$. The lower charge on $\mathrm{In}^{3+}$, compared with $\mathrm{Ge}^{4+}$ and $\mathrm{Sn}^{4+}$, makes it possible to form the required 3-coordinated sulfur site for the formation of T3 clusters. Moreover, the $\mathrm{In}^{3+}$ composition is extended to Ga-S, Ga-Se, and In-Se compositions by Feng'sgroup. $[11,17,33]$ The use of the nonaqueous synthesis method is responsible for the success in the syntheses of Ga-S composition. On the other hand, the synthesis of the $\left[\mathrm{Cd}_{4} \mathrm{In}_{16} \mathrm{~S}_{35}\right]_{14}$ in $\mathrm{T} 4$ cluster shows that the access of regular clusters larger than T3 is possible by the help of divalent cations, in addition to the In-S composition. [5]Moreover, the combination of monovalent (eg., $\left.\mathrm{Cu}^{+}\right)$and trivalent cations (eg., $\mathrm{In}^{3+}$ ) could provide the required local charge matching around the tetrahedral $\mathrm{S}^{2-}$ site. $[14,17]$

In terms of chemical compositions, metal chalcogenides tetrahedral molecular clusters with tetravalent $\left(\mathrm{M}^{4+}\right)$ and trivalent $\left(\mathrm{M}^{3+}\right)$ metal cations closely resembles the structure of aluminosilicate zeolites. The $\mathrm{M}^{4+} / \mathrm{M}^{3+}$ was not expected to be simple because eitherM $\mathrm{M}^{4+}$ or $\mathrm{M}^{3+}$ could independently form amine-directed crystals with sulfur and thus the probability of phase separation was high. $[7,17]$ Nevertheless, the use of the nonaqueous synthesis method could lead to the integration of $\mathrm{M}^{4+}$ and $\mathrm{M}^{3+}$ ions into the same framework. [11, 17, 33]A series of open framework sulfides and selenides were made by the combination of tetravalent (i. e., $\mathrm{Ge}^{4+}, \mathrm{Sn}^{4+}$ ) and trivalent metal (i. e., $\mathrm{Ga}^{3+}, \mathrm{In}^{3+}$ ) ions. [34] The $\mathrm{M}^{4+} / \mathrm{M}^{3+}$ ratio in these chalcogenides can be much smaller than that in zeolites. So far, the $\mathrm{M}^{4+} / \mathrm{M}^{3+}$ ratio falls within the range from 1.3 to 0.21 . Besides the low $\mathrm{M}^{4+} / \mathrm{M}^{3+}$ ratio in this series, some sulfides possess adequate stability toward ion exchange and thermal treatment. $[17,34]$

As mentioned in the above paragraph, the type of metal cations existed in the metal chalcogenides tetrahedral molecular clusters growth system shows a limitation on the formation of individual clusters. It is worth nothing to mention that cluster larger than T3 can be formed, if only trivalent cation isused in solvothermal system. However, if the synthesis is employedwith trivalent and divalent cations, the system has the flexibility to create a variety of clusters, such as T3, T4, and T5. [17]

\subsection{Structure-directing agent: Organic amines}

In oxides compounds, the oxygen sites of the anionic framework can form strong hydrogen bonding with $\mathrm{N}-\mathrm{H}$ groups of protonated amine molecules. [3] Such O...H-N bonding is an important factor in the directed assembly of oxide frameworks. The hydrogen bonding between chalcogenides frameworks and guest molecules (e. g., S...H-N) is very weak. [3]Based on the host-guest charge-density matching principle, proposed by Stucky et al., the content and distribution of heteroatoms in the framework can be adjusted by the guest species. [35] Thus, the co-assembly of metal chalcogenides tetrahedral molecular clusters with structuredirecting agent (guest), such as amine molecules, depends to a large extent on the host-guest 
electrostatic interaction. This principle can explain that open framework metal chalcogenides tetrahedral molecular generally have a rather negative framework and few neutral or nearly neutral open framework metal chalcogenides tetrahedral molecular are known today.

Interestingly, Yang et al. employ 4,4-trimethylene dipiperidine (TMDP), and histidine as the structure-directing agents for the synthesis of compound with mixed supertetrahedralchalcogenide clusters T2, and pentasupertetrahedralchalcogenide clusters P1, denoted as NCYU-5, (NCYUis named after National Chia Yi University), shown in Figure 6. [36]The TMDP is widely used as a structure construction template in the synthesis of Tn series chalcogenide clusters. [37] However, the use of amino acid in the hydrothermal synthesis for an inorganic tetrahedral cluster has not been reported. In this case, the porosity of the mixed chalcogenide clusters with a TMDP only template is about $55 \%$, smaller than the one with TMDP and histidine as templates. On the basis of experimental data, the role of histidine in the formation of mixed chalcogenide clusters is to improve the pore size of the 2-D framework, and the porosity of the crystal. The potential cavity occupied $67.1 \%$ of crystal cell volume can be calculated by the PLATON program. (a collection tool for single crystal structure analysis). The high percentage of cavity derived from NCYU-5 suggests that large amount of guest molecules, i. e. TMDP, and histidine, present in the structure of open frame work to make this material with high porosity. In each layer of the two dimensional open frame work of NCYU-5, alternating P1 and T2 clusters are linked together by bridging selenium atoms, Fig. 7(a). A triangle-shaped pore window is created by three T2 clusters, three P1 clusters, and six bridging Se atoms. The distance between the two corner Se atoms of the triangle-shaped window is 18.467(3) $\AA^{2}$, and the theoretical area of a triangle-shaped pore window is $147.6 \AA^{2}$, Fig. 7(b). The T2 clusters in one layer are located above or below the center of the 15-ring-window of its adjacent layers. The orientation of these T2 clusters is consistent. Although, these two-dimensional layers are stacked along the c-axis, the P1 clusters are located above or below P1 clusters of the adjacent layers with skewed orientation, Fig. 7(c). [36]

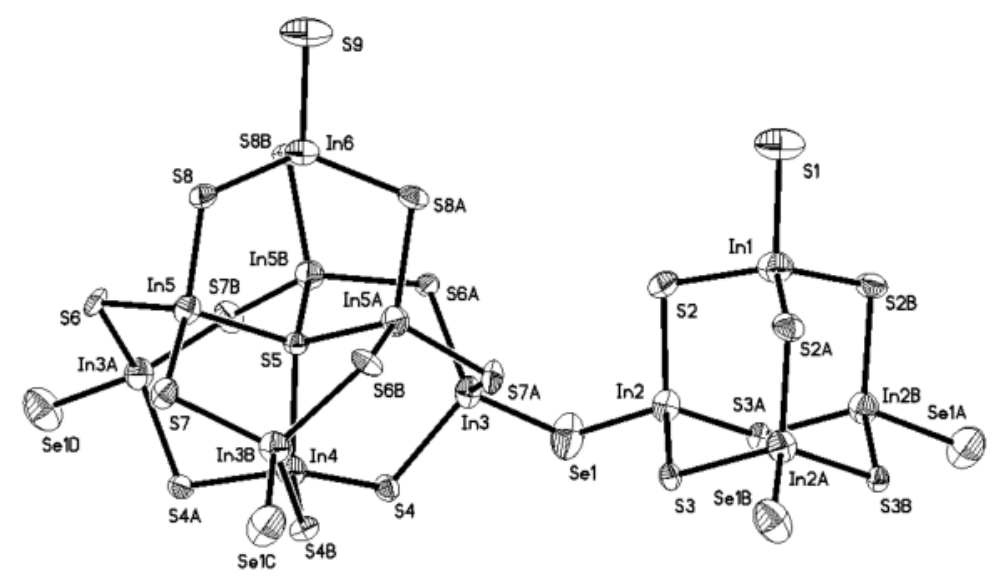

Figure 6. An illustrated unit cell structure for NCYU-5. The calculated occupancy possibility of the Se(1) site for Se to S is $\sim 90 \%$. The occupancy possibility of the S3 site in the T2 cluster for Se to S is 10\%. [36] 

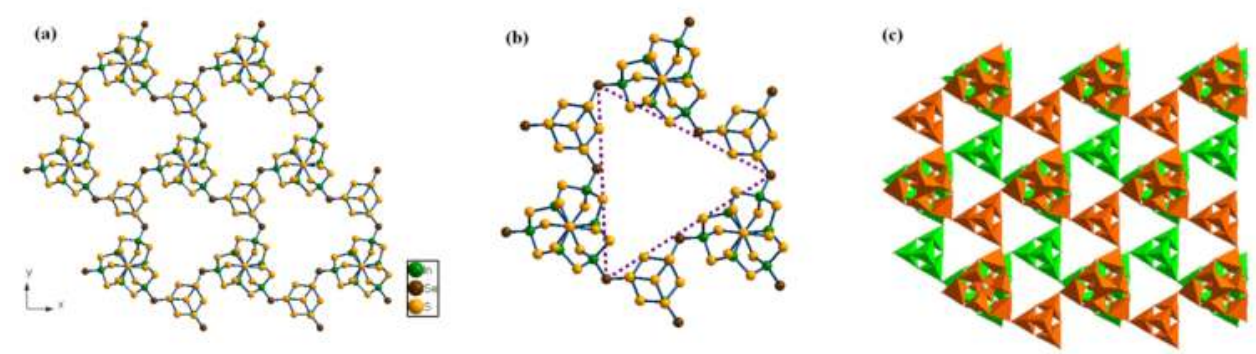

Figure 7. a) The 2-D open frame work of NCYU-5, alternating P1 and T2 clusters are linked together by bridging Se atoms. (b) The distance between the two corner Se atoms of the triangle-shaped window is $18.467 \AA^{2}$. The theoretical area of a triangle-shaped pore window is $147.6 \AA^{2}$. (c) Two adjacent layers stacked along c-axis. [36]

\subsection{Selected properties of metal chalcogenides tetrahedral molecular clusters}

\subsubsection{Thermal characteristics}

In the past decades, numerous metal chalcogenides tetrahedral molecular clusters have been successfully prepared. Although, these metal chalcogenides solids posses a wide range of compositions and topological features, the application potential is limited by the low thermal stability of these compounds. Up to present, not many metal chalcogenides tetrahedral molecular clusters can maintain the thermal stability in $500^{\circ} \mathrm{C}$ or higher, which is a required temperature to completely remove organic guest molecules through calcinations. [3] One example that can achieve the requirement is NCYU-5 that can maintain the crystal structure from room temperature (RT) to $505{ }^{\circ} \mathrm{C}$.. The thermogravimetric analysis (TGA) data of NCYU-5 is given in Figure 8. [36]The total weight loss is $26.72 \%$ from RT to $505{ }^{\circ} \mathrm{C}$. The initial weight loss of $3.09 \%$ from RT to $110{ }^{\circ} \mathrm{C}$ is because of the water desorption of surface. A sharp weight loss of $10.46 \%$ starting from $305{ }^{\circ} \mathrm{C}$ to $405{ }^{\circ} \mathrm{C}$ is attributed by the decomposition of two histidine molecules (calcd. 11. 5\%). The second sharp weight loss of $13.17 \%$ observed from $405{ }^{\circ} \mathrm{C}$ to $505{ }^{\circ} \mathrm{C}$ is possibly contributed by the decomposition of two TMDP molecules and the removal of $\mathrm{H}_{2} \mathrm{~S}$ (calcd. 15. 6\%). No further weight loss is observed after $505{ }^{\circ} \mathrm{C}$. The total recorded weight loss of $26.72 \%$ from $105{ }^{\circ} \mathrm{C}$ to $505{ }^{\circ} \mathrm{C}$ is in good agreement with the calculated weight loss (27. 1\%) for the guest molecules, i. e. one TMDP and one histidine in each unit cell of NCYU-5. As for the direct calcination of assynthesized samples by suitable temperature to remove a sizable fraction of extra-frame work organic components is shown in another example. In Feng et al. 's reported, $\sim 77 \%$ of nitrogen and $\sim 81 \%$ of hydrogen were removed from UCR-20GaGeS-TAEA, (TAEA = tris(2aminoethyl)amine, UCR = initials of University of California Riverside), by direct calcination at $350{ }^{\circ} \mathrm{C}$ with nitrogen gas. [34] However, the coke formation made the removal of carbon difficult, only $\sim 39 \%$ of carbon was removed from UCR-20GaGeS-TAEA in the same experiment. [34] 


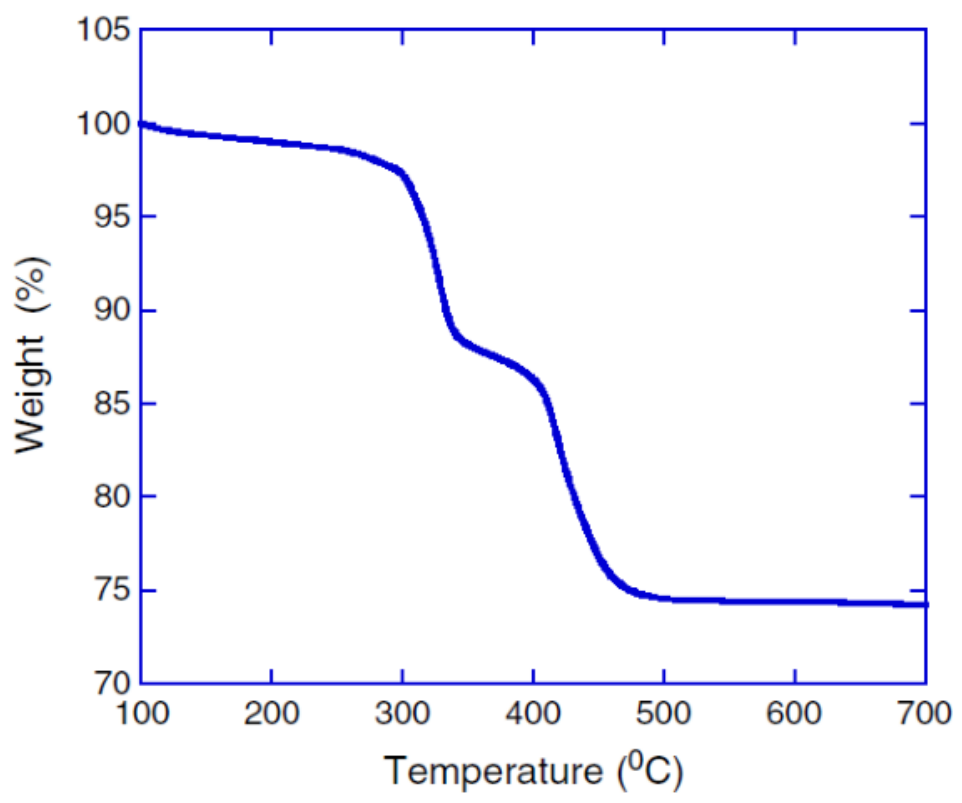

Figure 8. TGA data of NCYU-5. The total weight loss is $26.72 \%$ from RT to $800^{\circ} \mathrm{C}$. [36]

\subsubsection{Ion exchange}

Ion exchange is the most common properties of open framework solids. [38] This property has been shown for a number of metal chalcogenides tetrahedral molecular clusters, in which the protonated guests can be exchanged in solution by inorganic monocations (i. e., $\mathrm{Li}^{+}, \mathrm{Na}^{+}, \mathrm{K}^{+}, \mathrm{Rb}^{+}, \mathrm{Cs}^{+}$) and dications (i. e., $\mathrm{Mg}^{2+}, \mathrm{Ca}^{2+}, \mathrm{Sr}^{2+}, \mathrm{Ba}^{2+}$ ). After ion-exchange, microporosity of compound can be created by the removal of large organic cations. [34,39] For example, the ion-exchange with $\mathrm{Cs}^{+}$ions led to an almost complete removal of amine molecules from UCR-20GaGeS-TAEA. The $\mathrm{Cs}^{+}$-exchanged UCR-20GaGeS-TAEA exhibits the type I isotherm characteristic of a microporous solid (Figure 9). This sample has a high BET surface area $\left(807 \mathrm{~m}^{2} / \mathrm{g}\right)$ and a micropore volume $\left(0.23 \mathrm{~cm}^{3} / \mathrm{g}\right)$ despite the presence of much heavier elements (i. e., Cs, Ga, Ge, and S), compared with the analogues of aluminosilicate zeolites. [34]

\subsubsection{Conductivity}

An open-framework material has an inherent advantage for the applications in low-temperature fast-ion conductors. The existed open channels in these compounds provide the necessary paths for ions migration. Unfortunately, the sizeable open channels and cages contained in zeolites are not good fast-ion conductors because of the strong interaction between the oxygen framework and extra-framework charge carriers, such as $\mathrm{Li}^{+}$and $\mathrm{Na}^{+}$. [38] 
Open-framework metal chalcogenides tetrahedral molecular clusters are anticipated as better ion conductors than zeolites. The chalcogenides have higher anionic framework polarizability created by the large size of $\mathrm{S}^{2-}$ or $\mathrm{Se}^{2-}$, as compared with $\mathrm{O}^{2-}$. [1]The high polarizable anionic framework will facilitate the migration of mobile cations quick. Since the concentration of mobile cations is high in the open-framework metal chalcogenides tetrahedral molecular clusters. The chalcogenides clusters will have more negative frameworks for chargebalane than that of zeolites. The experimental data show that the framework $\mathrm{M}^{4+} / \mathrm{M}^{3+}$ (where $\mathrm{M}$ is a tetrahedral atom) ratio in chalcogenides is smaller than one, whereas the ratio value is always larger or equal to one in zeolites or related oxides. [3]For example, the synthesis of hydrated sulphides and selenides with highly mobile alkali or alkaline earth metal cations as extra framework cations, such as ICF-26. [3,22] The ionic conductivity of ICF-26 (Figure 10 ) is comparable to or exceeds previously known crystalline sodium or lithium conductors at RT and under relative humidity of $30 \%$ or higher. The highest specific conductivity achieved among open framework chalcogenides is $0.15 \Omega^{-1} \mathrm{~cm}^{-1}$ at $27^{\circ} \mathrm{C}$ and under $100 \%$ relative humidity. [3,40]

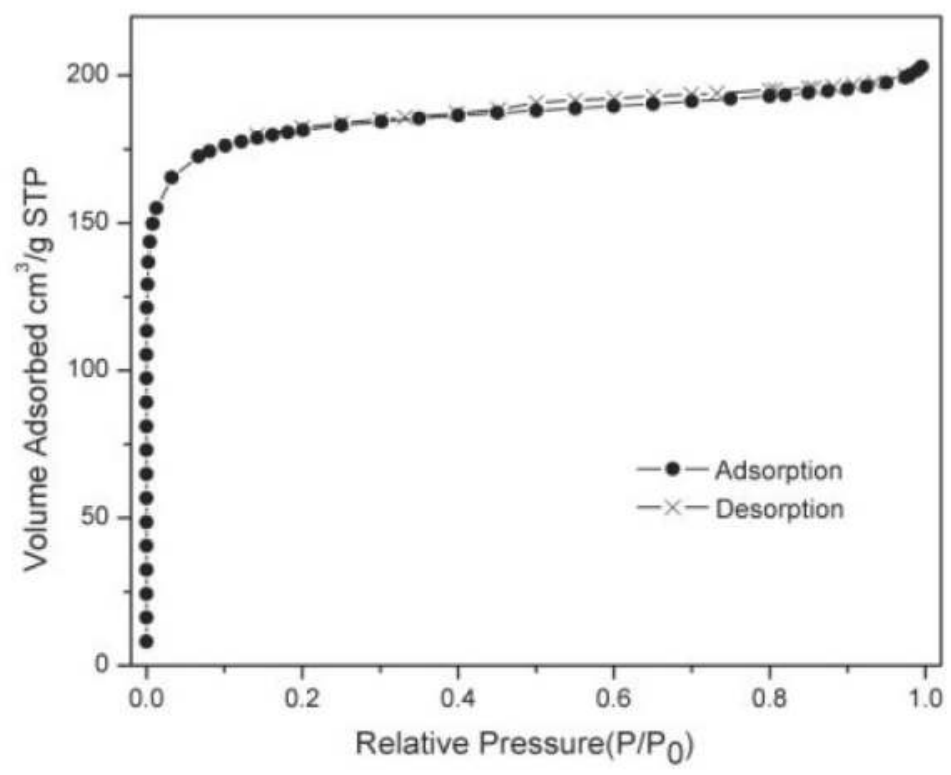

Figure 9. Nitrogen adsorption and desorption isotherms measured at $77 \mathrm{~K}$ for the $\mathrm{Cs}^{+}$exchanged UCR-20GaGeSTAEA. [34] 


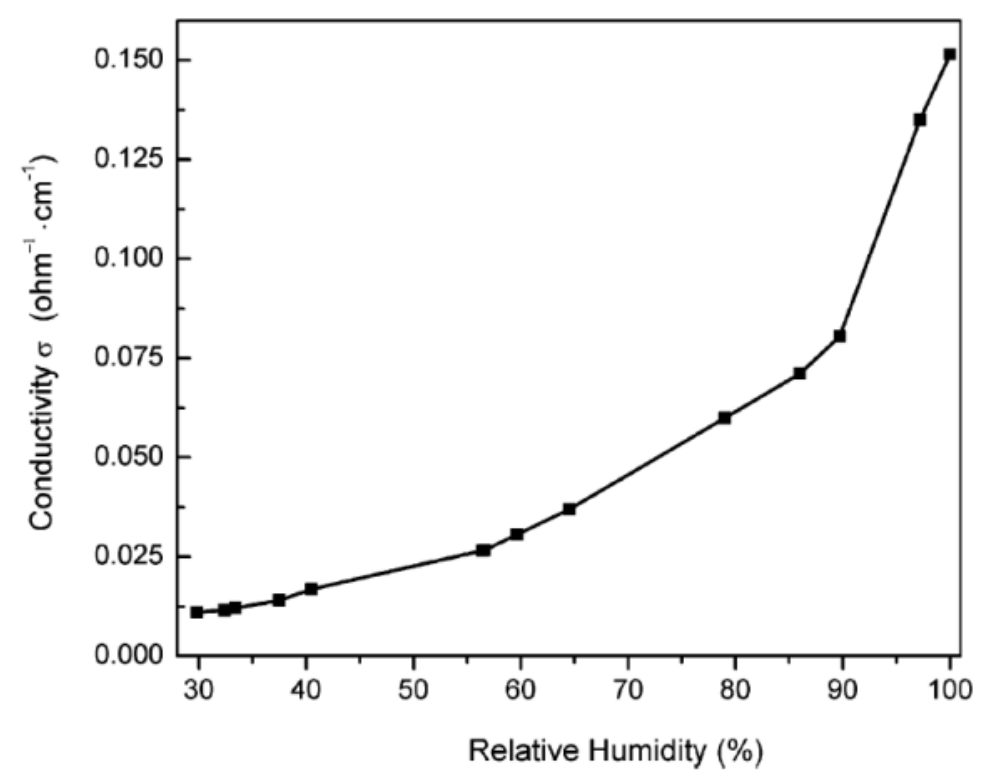

Figure 10. The ionic conductivity of ICF-26 under different relative humidity. Ionic conductivities were measured on a single crystal (cross section $0.37 \times 0.43 \mathrm{~mm}^{2}$, length $0.63 \mathrm{~mm}$ ). [3]

\subsubsection{Optical properties}

Most open framework chalcogenides without the incorporation with organic dyes or metal activators still can display photoluminescence with tunable emission wavelengths ranging almost continuously from 450 to $600 \mathrm{~nm}$. [41]The luminescence of open framework chalcogenidesis known to be related with the highly negatively charged inorganic framework and the presence of protonated guest amine molecules. [41, 42] On the top of this review point, Se exhibits a better induced optoelectronic property than $S$ because the ionization energy barrier of Se is much lower than that of S. [36, 43, 44] Based on this understanding, Yang et al. prepared the Se doped metal chalcogenides tetrahedral molecular clusters, i. e. NCYU family, to study the optoelectronic luminescent phenomena induced by the quantum confinement of Se in these clusters. The clusters prepared by Yang's group include NCYU-1 (T4/Se), NCYU-3 (T3/Se), and NCYU-5 (mixed P1+T2/Se). [36, 43, 44]Two PL emission peaks, centered at about $457 \mathrm{~nm}$ and $538 \mathrm{~nm}$, were revealed from the NCYU-3(T3/Se). But only the $457 \mathrm{~nm}$ peak is observed in the spectra of NCYU-InS-AEAE (T3) (AEAE= 2-(2-aminoethylamino)ethanol) and NCYU-4 (T3). The peak at $457 \mathrm{~nm}$ has been reported for the luminescence of open framework chalcogenides. Thus, the trace Se atoms confined in the NCYU-3 (T3/Se) supertetrahedral clusters is responsible for the newly discovered $538 \mathrm{~nm}$ emission peak (Figure 11). [44] 


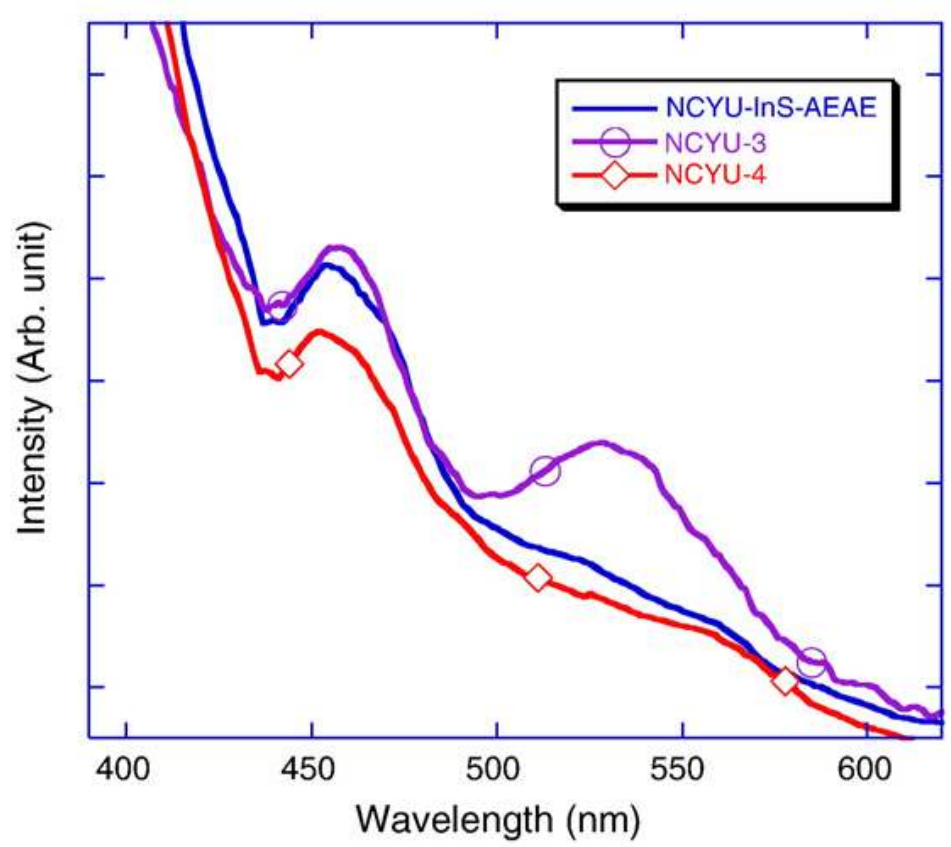

Figure 11. The RT PL spectra for NCYU-T3 family. Two emission peaks, centered at about $457 \mathrm{~nm}$ and $538 \mathrm{~nm}$, were revealed from the NCYU-3. [44]

On the other hand, a family of discrete chalcogenide T4 clusters $\left[\mathrm{M}_{\mathrm{x}} \mathrm{Ga}_{18-\mathrm{x}} \mathrm{Sn}_{2} \mathrm{Q}_{35}\right]^{12-[45]}$ ( $\mathrm{x}=2$ or 4; $\mathrm{M}=\mathrm{Mn}, \mathrm{Cu}, \mathrm{Zn} ; \mathrm{Q}=\mathrm{S}$, Se), prepared by Feng's group, show an unusual phase transformation from a T4 covalent framework (3-D) into T4 molecular clusters (0-D), denoted as OCF-5s or OCF-40s (OCF stands for organically directed chalcogenide frameworks). In the case of OCF-40s, these iso-structural compounds show a remarkable effect of different $\mathrm{d}^{10}$ metal ions $\left(\mathrm{Cu}^{+}\right.$and $\left.\mathrm{Zn}^{2+}\right)$ and chalcogen anions $\left(\mathrm{Se}^{2-}\right.$ and $\left.\mathrm{S}^{2-}\right)$ on the sample colors and band gap of semiconductor materials. The UV-vis diffuse reflectance spectrum reveals that the dark red selenide sample of OCF-40-CuGaSnSe-PR (formula: $\left[\mathrm{Cu}_{2} \mathrm{Ga}_{16} \mathrm{Sn}_{2} \mathrm{Se}_{35}\right]$ 12( $\left.\mathrm{C}_{5} \mathrm{NH}_{12}\right)$, $\mathrm{PR}=$ piperidine) has a wider UV-vis adsorption peak thanthe yellow sample of OCF-40$\left.\mathrm{ZnGaSnSe-PR.} \mathrm{(formula:[} \mathrm{Zn}_{4} \mathrm{Ga}_{14} \mathrm{Sn}_{2} \mathrm{Se}_{35}\right] 12\left(\mathrm{C}_{5} \mathrm{NH}_{12}\right)$ ). A similar difference is also found in sulfides analogues between OCF-40-CuGaSnS-PR (formula: $\left[\mathrm{Cu}_{2} \mathrm{Ga}_{16} \mathrm{Sn}_{2} \mathrm{~S}_{35}\right] 12\left(\mathrm{C}_{5} \mathrm{NH}_{12}\right)$ ) and OCF-40-ZnGaSnS-PR. (formula:[ $\left[\mathrm{Zn}_{4} \mathrm{Ga}_{14} \mathrm{Sn}_{2} \mathrm{~S}_{35}\right]$ 12( $\left.\mathrm{C}_{5} \mathrm{NH}_{12}\right)$ ). The solid-state diffuse reflectance spectra, shown in Figure 12, show that OCF-40s are semiconductors with different band gaps(bg): OCF-40-CuGaSnSe-PR, bg = 1. 91 eV; OCF-40-ZnGaSnSe-PR, bg = 2. $71 \mathrm{eV}$; OCF-40-CuGaSnS-PR, bg = 2. $11 \mathrm{eV}$; and OCF-40-ZnGaSnS-PR, bg = 3. $59 \mathrm{eV}$. The experimental data show that metal chalcogenides tetrahedral molecular clusters with $\mathrm{Cu}^{+}$and $\mathrm{Se}^{2-}$ in the framework will have much lower band gaps. [45] 


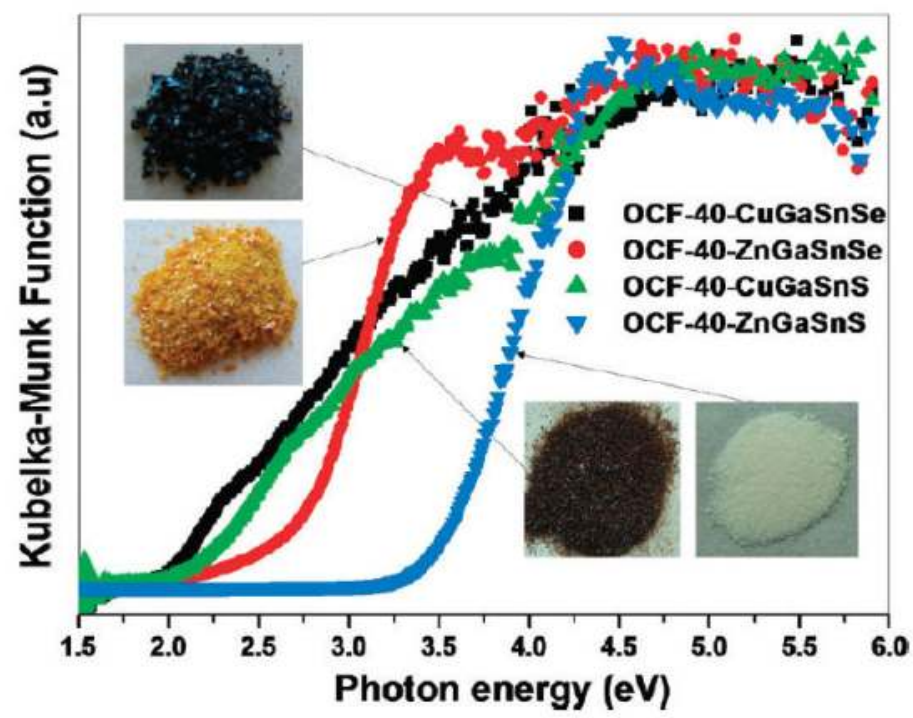

Figure 12. Effects of $\mathrm{Cu}^{+} \mathrm{vs} \mathrm{Zn}^{2+}$ and $\mathrm{Se}^{2-} \mathrm{vs} \mathrm{S}^{2-}$ on band structures in solid state: normalized solid-state UV-vis absorption spectra of OCF-40s. Insets are photos of the as-synthesized crystalline materials. [45]

\subsubsection{Photocatalytic applications}

Over the past few decades, a large family of crystalline porous materials based on metal chalcogenides were developed. [3-7,36,43,44]These materials integrate tunable band gaps with an open-framework architecture and are potential candidates for efficient photocatalysts due to their optical properties. By controlling framework architecture, it is possible to tune the band structure (both band positions and gap) of an open-framework solid within a given compositional domain. The open-framework construction can increase the number of active reaction sites by the high surface area. [46] In order to evaluate catalytic efficiency for hydrogen generation by metal chalcogenides tetrahedral molecular clusters, a series of porous crystalline open-framework sulfides, such as ICF-17MnInS-Na (formula: $\mathrm{Na}_{16^{-}}$ $\mathrm{Mn}_{13} \mathrm{In}_{22} \mathrm{~S}_{54} \times \mathrm{H}_{2} \mathrm{O}$ ) or ICF-5CdInS-Na (formula: $\mathrm{Na}_{10}-\mathrm{Cd}_{4} \mathrm{In}_{16} \mathrm{~S}_{33} \times \mathrm{H}_{2} \mathrm{O}$ ), are prepared by Feng's group. [46]Under the irradiation of visible light, ICF-5CdInS-Nais photocatalytically active without the use of a co-catalyst, such as Pt. As shown in Figure 13, about $18 \mathrm{mmolh}^{-1} \mathrm{~g}^{-1} \mathrm{of} \mathrm{H}_{2}$ gas was produced over the ICF-5CuInS-Na catalyst under irradiation with the visible light. This activity was maintained for over $96 \mathrm{~h}$ and more than $890 \mathrm{mmol}$ of $\mathrm{H}_{2}$ gas evolved during this period. The quantum efficiency for ICF-5CuInS-Na was about 3. 7\% at $420 \mathrm{~nm}$. Even though the number is lower than the quantum yield( $35 \%)$ of the well-known Pt/CdS photocatalyst, the efficiency is a considerable improvement on two anhydrous dense phases with similar compositions: $\mathrm{CuInS}_{2}$ with the cubic $\mathrm{ZnS}$ structure, and $\mathrm{CuIn}_{5} \mathrm{~S}_{8}$ with the spinel structure. 


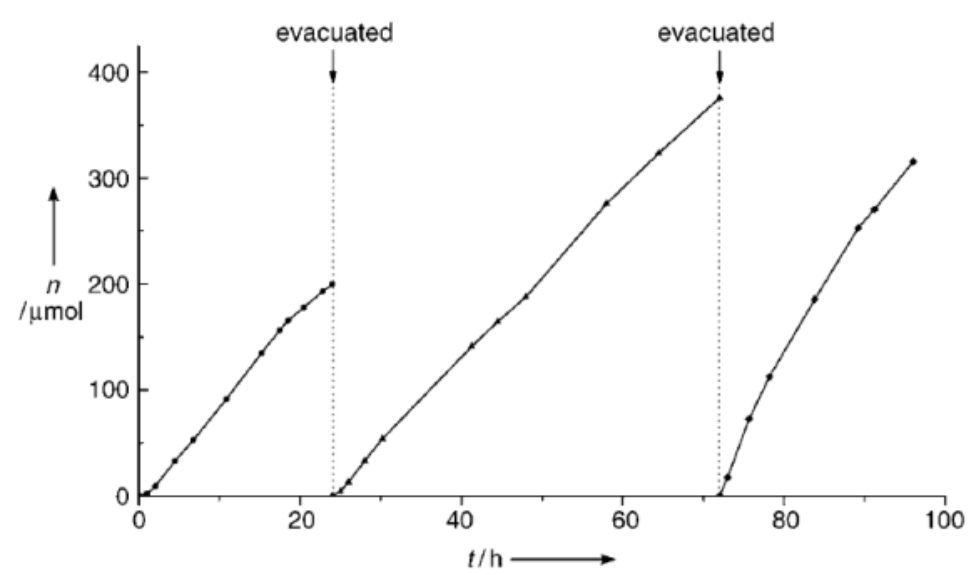

Figure 13. Photocatalytic $\mathrm{H}_{2}$ evolution from an aqueous solution of $\mathrm{Na}_{2} \mathrm{~S}(0.5 \mathrm{M})$ over ICF-5 CulnS-Na (0. $\left.5 \mathrm{~g}\right)$; t: irradiation time, n:amount of $\mathrm{H}_{2}$. [46]

\section{Author details}

Chun-Chang Ou and Chung-Sung Yang*

*Address all correspondence to: csyang@mail. ncyu. edu. tw

Department of Applied Chemistry, National Chia Yi University, Taiwan, ROC

\section{References}

[1] Sokolov, M. N. Metal Chalcogenides. In Handbook of Chalcogen Chemistry: New Perspectives in Sulfur, Selenium and Tellurium; Devillanova, F. A.; Royal Society of Chemistry: Cambridge U.K., 2007; p543.

[2] Férey, G. Supertetrahedra in Sulfides: Matter against mathematical series? Angew. Chem., Int. Ed. 2003, 42, 2576-257.

[3] Feng, P.; Bu, X.; Zheng, N. The Interface Chemistry between Chalcogenide Clusters and Open Framework Chalcogenides. Acc. Chem. Res. 2005, 38, 293-303.

[4] Li, H.; Laine, A.; O'Keeffe, M.; Yaghi, O. M. Supertetrahedral sulfide crystals with giant cavities and channels. Science 1999, 283, 1145-1147. 
[5] Li, H.; Kim, J.; Groy, T. L.; O’Keeffe, M.; Yaghi, O. M. $20 \AA \mathrm{Cd}_{4} \mathrm{In}_{16} \mathrm{~S}_{35}{ }^{14-}$ Supertetrahedral T4 Clusters as Building Units in Decorated Cristobalite Frameworks. J. Am. Chem. Soc. 2001, 123, 4867-6868.

[6] Dance, I. G.; Choy, A.; Scudder, M. L. Syntheses, Properties, and Molecular and Crystal Structures of $\left(\mathrm{Me}_{4} \mathrm{~N}\right)_{4}\left[\mathrm{E}_{4} \mathrm{M}_{10}(\mathrm{SPh})_{16}\right](\mathrm{E}=\mathrm{S}, \mathrm{Se} ; \mathrm{M}=\mathrm{Zn}, \mathrm{Cd})$ : Molecular Super-tetrahedral Fragments of the Cubic Metal Chalcogenide Lattice. J. Am. Chem. Soc. 1984, $106,6285-6295$.

[7] Yaghi, O. M.; Sun, Z.; Richardson, D. A.; Groy, T. L. Directed Transformation of Molecules to Solids: Synthesis of a Microporous Sulfide from Molecular Germanium Sulfide Cages. J. Am. Chem. Soc. 1994, 116, 807-808.

[8] Krebs, B.; Voelker, D.; Stiller, K. Novel Adamantane-lie Thio- and Selenoanions from Aqueous Solutions: $\mathrm{Ga}_{4} \mathrm{~S}_{10}{ }^{8-}, \mathrm{In}_{4} \mathrm{~S}_{10}{ }^{8-}, \mathrm{In}_{4} \mathrm{Se}_{10}{ }^{8-}$. Inorg. Chim. Acta 1982, 65, L101-L102.

[9] Ahari, H.; Garcia, A.; Kirkby, S.; Ozin, G. A.; Young, D.; Lough, A. J. Self-assembling iron and manganese metal-germaniumselenide framework: $\left[\mathrm{NMe}_{4}\right]_{2} \mathrm{MGe}_{4} \mathrm{Se}_{10}$, where M = Fe or Mn. J. Chem. Soc., Dalton Trans. 1998, 2023-2027.

[10] Pirani, A. M.; Mercier, P. A.; Dixon, D. A.; Borrmann, H.; Schrobilgen, G. J. Syntheses, Vibrational Spectra, and Theoretical Studies of the Adamantanoid $\mathrm{Sn}_{4} \mathrm{Ch}_{10}{ }^{4-}$ (Ch $=$ Se, Te) Anions: X-ray Crystal Structures of [18-Crown-6-K $]_{4}\left[\mathrm{Sn}_{4} \mathrm{Se}_{10}\right] \cdot 5 \mathrm{en}$ and [18rown-6-K $]_{4}\left[\mathrm{Sn}_{4} \mathrm{Te}_{10}\right] \cdot 3 e n \cdot 2 \mathrm{THF}$. Inorg. Chem. 2001, 40, 4823- 4829.

[11] Zheng, N.; Bu, X.; Feng, P. Nonaqueous Synthesis and Selective Crystallization of Gallium Sulfide Clusters into Three-Dimensional PhotoluminescentSuperlattices. J. Am. Chem. Soc. 2003, 125, 1138-1139.

[12] Vaqueiro, P.; Romero, M. L. $\left[\mathrm{Ga}_{10} \mathrm{~S}_{16}\left(\mathrm{NC}_{7} \mathrm{H}_{9}\right)_{4}\right]^{2-}:$ a hybrid supertetrahedralnanocluster. Chem. Commun., 2007, 3282-3284.

[13] Wang, C.; Li, Y.; Bu, X.; Zheng, N.; Zivkovic, O.; Yang, C.; Feng, P. Three-Dimensional Superlattices Built from $\left(\mathrm{M}_{4} \mathrm{In}_{16} \mathrm{~S}_{33}\right)^{10-}(\mathrm{M}=\mathrm{Mn}, \mathrm{Co}, \mathrm{Zn}, \mathrm{Cd})$ Supertetrahedral Clusters. J. Am. Chem. Soc. 2001, 123, 11506-11507.

[14] Bu, X.; Zheng, N.; Li, Y.; Feng, P. Pushing Up the Size Limit of ChalcogenideSupertetrahedral Clusters: Two- and Three-Dimensional Photoluminescent Open Frameworks from $\left(\mathrm{Cu}_{5} \mathrm{In}_{30} \mathrm{~S}_{54}\right)^{13-}$ Clusters. J. Am. Chem. Soc. 2002, 124, 12646-12647.

[15] Wang, C.; Bu, X.; Zheng, N.; Feng, P. Nanocluster with One Missing Core Atom: A Three-Dimensional Hybrid Superlattice Built from Dual-Sized Supertetrahedral Clusters. J. Am. Chem. Soc. 2002, 124, 10268-10269.

[16] Su, W.; Huang, X.; Li, J.; Fu, H. Crystal of Semiconducting Quantum Dots Built Upon Covalently Bonded T5 $\left[\operatorname{In}_{28} \mathrm{Cd}_{6} \mathrm{~S}_{54}\right]^{-12}$ : The Largest Supertetrahedral Cluster in Solid State. J. Am. Chem. Soc. 2002, 124, 12944-12945.

[17] Bu, X.; Zheng, N.; Feng, P. Tetrahedral Chalcogenide Clusters and Open Frameworks. Chem. Eur. J. 2004, 10, 3356-3362. 
[18] Lee, G. S. H. ; Craig, D. C.; Ma, I.; Scudder, M. L.; Bailey, T. D.; Dance, I. G. $\left[\mathrm{S}_{4} \mathrm{Cd}_{17}(\mathrm{SPh})_{28}\right]^{2-}$, the First Member of a Third Series of Tetrahedral $\left[\mathrm{S}_{\mathrm{w}} \mathrm{M}_{\mathrm{x}}(\mathrm{SR})_{\mathrm{y}}\right]^{\mathrm{z-}}$ Clusters. J. Am. Chem. Soc. 1988, 110, 4864-4866.

[19] Palchik, O.; Iyer, R.G.; Liao, J. H.; Kanatzidis, M. G. $\mathrm{K}_{10} \mathrm{M}_{4} \mathrm{Sn}_{4} \mathrm{~S}_{17}(\mathrm{M}=\mathrm{Mn}, \mathrm{Fe}, \mathrm{Co}, \mathrm{Zn})$ : Soluble Quaternary Sulfides with the Discrete $\left[\mathrm{M}_{4} \mathrm{Sn}_{4} \mathrm{~S}_{17}\right]^{10-S u p e r t e t r a h e d r a l ~ C l u s t e r s . ~}$ Inorg. Chem. 2003, 42, 5052-5054.

[20] Dehnen, S.; Brandmayer, M. K. Reactivity of Chalcogenostannate Compounds: Syntheses, Crystal Structures, and Electronic properties of Novel Compounds Containing Discrete Ternary Anions $\left[\mathrm{M}_{4}^{\mathrm{II}}\left({ }_{\mu 4}-\mathrm{Se}\right)\left(\mathrm{SnSe}_{4}\right)_{4}\right]^{10-}\left(\mathrm{M}^{\mathrm{II}}=\mathrm{Zn}, \mathrm{Mn}\right)$. J. Am. Chem. Soc. 2003, 125, 6618-6619.

[21] Zimmermann, C.; Melullis, M.; Dehnen, S. Reactivity of Chalcogenostannate Salts: Unusual Synthesis and Structure of a compound Containing Ternary Cluster Anions $\left[\mathrm{Co}_{4}\left({ }_{\mu 4}-\mathrm{Se}\right)-(\mathrm{SnSe})_{4}\right]^{10-}$. Angew. Chem., Int. Ed. 2002, 41, 4269-4272.

[22] Zheng, N.; Bu, X.; Feng, P. Penta-Supertetrahedral Clusters as Building Blocks for Three-Dimensional Sulfide Superlattice. Angew. Chem., Int. Ed. 2004, 43, 4753-4755.

[23] Eichhofer, A.; Fenske, D. Syntheses and structures of new copper- (I)-indium(III)-selenide clusters. J. Chem. Soc., Dalton Trans. 2000, 941-944.

[24] Vossmeyer, T.; Reck, G.; Katsikas, L.; Haupt, E. T. K.; Schulz, B.; Weller, H. A Double Diamond Superlattice Built Up of $\mathrm{Cd}_{17} \mathrm{~S}_{4}\left(\mathrm{SCH}_{2}-\mathrm{CH}_{2} \mathrm{OH}\right)_{26}$. Science 1995, 267, 1476-1479.

[25] Jin, X.; Tang, K.; Jia, S.; Tang, Y. Synthesis and Crystal Structure of a polymeric Complex $\left[\mathrm{S}_{4} \mathrm{Cd}_{17}(\mathrm{SPh})_{24}\left(\mathrm{CH}_{3} \mathrm{OCS}_{2}\right)_{4 / 2}\right] \mathrm{n} \cdot \mathrm{nCH}_{3} \mathrm{OH}$. Polyhedron 1996, 15, 2617-2218.

[26] Vossmeyer, T.; Reck, G.; Schulz, B.; Katsikas, L.; Weller, H. Double-Layer Superlattice Structure Built Up of $\mathrm{Cd}_{32} \mathrm{~S}_{14}\left(\mathrm{SCH}_{2} \mathrm{CH}(\mathrm{OH})-\mathrm{CH}_{3}\right)_{36} \cdot 4 \mathrm{H}_{2} \mathrm{O}$ Clusters. J. Am. Chem. Soc. 1995, 117, 12881-12882.

[27] Herron, N.; Calabrese, J. C.; Farneth, W. E.; Wang, Y. Crystal structure and optical properties of $\mathrm{Cd}_{32} \mathrm{~S}_{14}\left(\mathrm{SC}_{6} \mathrm{H}_{5}\right)_{36} \cdot \mathrm{DMF}_{4}$, a cluster with a 15 angstrom cadmium sulfide core. Science 1993, 259, 1426-1428.

[28] Behrens, S.; Bettenhausen, M.; Deveson, A. C.; Eichhofer, A.; Fenske, D.; Lohde, A.; Woggon, U. Synthesis and Structure of the Nanoclusters $\left[\mathrm{Hg}_{32} \mathrm{Se}_{14}(\mathrm{SePh})_{36}\right]$, $\left[\mathrm{Cd}_{32} \mathrm{Se}_{14}(\mathrm{SePh})_{36}(\mathrm{PPh})_{4}\right], \quad\left[\mathrm{P}(\mathrm{Et})_{2}-(\mathrm{Ph}) \mathrm{C}_{4} \mathrm{H}_{8} \mathrm{OSiMe}_{3}\right]_{5}\left[\mathrm{Cd}_{18} \mathrm{I}_{17}\left(\mathrm{PSiMe}_{3}\right)_{12}\right], \quad$ and $\left[\mathrm{N}(\mathrm{Et})_{3} \mathrm{C}_{4} \mathrm{H}_{8} \mathrm{OSiMe}_{3}\right]_{5}-\left[\mathrm{Cd}_{18} \mathrm{I}_{17}\left(\mathrm{PSiMe}_{3}\right)_{12}\right]$. Angew. Chem., Int. Ed. 1996, 35, 2215-2218

[29] Li, H.; Kim, J.; O'Keeffe, M.; Yaghi, O. M. $\left[\mathrm{Cd}_{16} \operatorname{In}_{64} \mathrm{~S}_{134}\right]^{44-}$ : 31-Å. tetrahedron with a large cavity. Angew. Chem., Int. Ed. 2003, 42, 1819-1821

[30] Vaqueiro, P. Hybrid materials through linkage of chalcogenide tetrahedral clusters. Dalton Trans. 2010, 39, 5965-5972. 
[31] Choy, A.; Craig, D.; Dance, I. G.; Scudder, M. L. $\left[\mathrm{S}_{4} \mathrm{M}_{10}(\mathrm{SPh})_{16}\right]^{4-}(\mathrm{M}=\mathrm{Zn}, \mathrm{Cd})$, a Molecular Fragment of the Sphalerite MS Lattice: Structural Congruence of Metal Sulphides and Metal Thiolates. J. Chem. Soc., Chem. Comm. 1982, 21, 1246-1248.

[32] Feng, P.; Bu, X.; Stucky, G. D. Hydrothermal syntheses and structural characterization of zeolite analogue compounds based on cobalt phosphate. Nature 1997, 388, 735-741.

[33] Bu, X.; Zheng, N.; Wang, X.; Wang, B.; Feng, P. Three-Dimensional Frameworks of Gallium SelenideSupertetrahedral Clusters. Angew. Chem. Int. Ed. 2004, 43, 1502-1505.

[34] Zheng, N.; Bu, X.; Wang, B.; Feng, P. Microporous and PhotoluminescentChalcogenide Zeolite Analogues. Science 2002, 298, 2366-2369.

[35] Feng, P.; Bu, X.; Stucky, G. D. Hydrothermal syntheses and structural characterization of zeolite analogue compounds based on cobalt phosphate. Nature 1997, 388, 735-741.

[36] Chen,C.; Ou, C.; Huang, H.; Cheng, J; Yang, C. Mixed pentasupertetrahedral P1 and supertetrahedral T2 clusters as building units to create two-dimensional indium chalcogenides open framework. Inorg. Chem. Commun. 2011, 14, 1004-1009.

[37] Zhang, Q.; Bu, X.; Han, L.; Feng, P. Two-Dimensional Indium Sulfide Framework Constructed from Pentasupertetrahedral P1 and Supertetrahedral T2 Clusters. Inorg. Chem. 2006, 45, 6684-6687.

[38] Flanigen, E. M. Zeolites and Molecular Sieves. An Historical Perspective. In Introduction to Zeolite Science and Practice; van Bekkum, H., Flanigen, E. M., Jansen, J. C., Eds.; Elsevier: New York, 1991; 13-34.

[39] Li, H.; Eddaoudi, M.; Laine, A. O'Keeffe, M.; Yaghi, O. M. Noninterpenetrating Indium Sulfide SupertetrahedralCristobalite Framework. J. Am. Chem. Soc. 1999, 121, 6096-6097.

[40] Zheng, N.; Bu, X.; Feng, P. Synthetic design of crystalline inorganic chalcogenides exhibiting fast-ion conductivity. Nature 2003, 426, 428-432.

[41] Feng, P. Photoluminescence of open-framework phosphates and germinates. Chem. Commun. 2001, 1668-1669

[42] Zheng, N.; Bu, X.; Feng, P. Self-Assembly of Novel Dye Molecules and $\left[\mathrm{Cd}_{8}(\mathrm{SPh})_{12}\right]^{4+}$ Cubic Clusters into Three-Dimensional PhotoluminescentSuperlattice. J. Am. Chem. Soc. 2002, 124, 9688-9689.

[43] Chen, C.; Yang, C.; Lin, X. Synthesis, characterization, and photoluminescence of quaternary $\left[\mathrm{Cd}_{4} \mathrm{In}_{16} \mathrm{~S}_{33-\mathrm{x}} \mathrm{Se}_{\mathrm{x}}\right]^{10-}$ supertetrahedral clusters: $(0.33<\mathrm{x}<0.45)$. Inorg. Chem. Commun. 2005, 8, 836-840.

[44] Yang, C.; Su, Y.; Wang, Y.; Cheng, J.; Lin, X. Synthesis of three dimensional photoluminescent $\left[\operatorname{In}_{10} \mathrm{~S}_{20-\mathrm{x}} \mathrm{Se}_{\mathrm{x}}\right]^{10-}$ supertetrahedral clusters: $(\mathrm{x}<0.3)$. Mater. Lett. 2008, 62, 4015-4017. 
[45] Wu, T., Wang, L., Bu, X., Chau, V., Feng, P. Largest Molecular Clusters in the SupertetrahedralTn Series. J. Am. Chem. Soc.2010, 132, 10823-10831.

[46] Zheng, N., Bu, X., Vu, H., Feng, P. Open-Framework Chalcogenides as Visible-Light Photocatalysts for Hydrogen Generation from Water. Angew. Chem. 2005, 117, 5433 5437. 
